\title{
ANDRADE, DARÍO, LUGONES. Indecidibilidad, modernidad y poesía
}

Susana Scramim

Universidade Federal de Santa Catarina / CNPq

Este texto quiere señalar que lo que se comprendió como causa de la modernidad secuestrada en América Latina, o sea, las máscaras del modernismo como causa de una modernidad periférica, fuera de lugar etc., no actuó como impeditivo de una auténtica modernidad, o una modernidad democrática civilizada occidental en esta parte del continente americano, sino actuó y actúa como una contrafaz inherente al proceso de modernización no sólo de América Latina sino que es la contrafaz de la modernidad en el occidente.

Para pensar las máscaras de la modernidad retomo la lectura de dos figuras importantes de la literatura dramática latino-americana: Pierrot y Arlequín. Más allá de que sean personajes, son también tópicas de la literatura del fin del siglo XIX. Como personajes, son personas, pero son también imagen del sujeto dividido de la modernidad. Las máscaras en el teatro griego servían para donar a los actores su personaje, su persona, su máscara que, en griego, quiere decir persona. Además, las máscaras eran tipificadas, siempre correspondiendo a un personaje preestablecido. Escondiendo el rostro, los actores representaban usando apenas el ton de voz y el gesto. De cierta manera, el maquillaje y la guardarropía mantienen la idea de máscara, porque se constituyen en gestos en la escena.

No por acaso, Ángel Rama en uno de sus textos publicados póstumamente, Las máscaras democráticas del modernismo (1985), retoma, bajo otra mirada, aquello que afirmara en Rubén Darío y el modernismo (1970). Cuando estudia Rubén Darío en 1970 nos dice que hay antecedentes para que la lengua poética de Darío fuera lo que fuera, o sea, portadora de un conocimiento minucioso de las técnicas poéticas y con una capacidad de transmutación artística incomparable; y que los antecedentes de Darío, eran además de los autores 
Groussac, Martí, Francisco Gaviria, Pedro Balmaceda, toda la literatura decadente, moderna y francesa. Entretanto, Rama señala un problema de escala entre las dos modernidades, la francesa y la latinoamericana:

Pero en la medida en que asume las experiencias anteriores, las somete a reelaboración subjetiva intensa, las exacerba hasta un extremismo muy peculiarmente hispanoamericano en su conducta con las corrientes culturales europeas, y las marca soberanamente con las condiciones de la literatura moderna francesa; establece el tipo de imperio que impuso Lope a la dramaturgia de su tiempo, y se constituye, según el decir cervantino, en "un monstruo de la naturaleza. (Rama, 1970:9)

La singularidad de la literatura hispanoamericana pasaba en el joven Ángel Rama por un pensamiento extremo que llevaba a una exacerbación de la literatura moderna francesa tomada como el modelo ejemplar de la cultura occidental europea. Sobre este tipo de comportamiento de la crítica literaria y cultural de aquellos críticos que se filian a un pensamiento autonomista del arte, con sus premisas de progresismo democrático totalizantes, sería interesante que recodáramos de la lectura de Walter Benjamin sobre el drama barroco alemán.

Cuando entre los años de 1915 y 1925 Benjamin estaba preparando el estudio sobre el drama barroco compartía con su época el interés sobre la cultura del siglo XVII. En la introducción del libro, Benjamin ya describe el contexto de las lecturas decimononas sobre el barroco del siglo XVII. Eran lecturas historicistas, autonomistas y progresistas que quieren ver en el Barroco una etapa degenerada del proceso de desarrollo de la modernidad en Europa que empezaría con el Renacimiento. Benjamin nos dice que la crítica de fines de siglo XIX del Barroco del XVII adaptaba la teoría aristotélica del drama para las tendencias de época. De ese modo, los dramas barrocos aparecían o reaparecían en la historiografía literaria como mera caricatura de la tragedia antigua:

Pues dentro de este esquema se quería encajar sin dificultad aquello que a un gusto refinado se le antojaba extraño, bárbaro incluso, en aquellas obras. Las acciones principales y de Estado distorsionaban sobre el fondo del antiguo drama de los reyes; el engolamiento destruía lo que fue el noble páthos de los helenos, y el sangriento efecto conclusivo desvirtuaba la catástrofe trágica. El Trauerspiel se presentaba así como el torpe renacimiento de la tragedia. De ese modo se impuso una nueva clasificación que tenía que frustrar enteramente toda posible visión de dicha forma: considerado como drama del Renacimiento, el Trauerspiel aparece afectado en sus rasgos característicos por otros tantos defectos 
estilísticos. Debido a la autoridad de unos registros temáticos elaborados con un criterio histórico, este inventario estuvo por mucho tiempo sin rectificar. (Benjamin, 2006:248)

Benjamin nos está diciendo que el drama barroco fue considerado por la crítica como remake, una copia, y mal hecha, de la tragedia antigua, y ¿quién tendría llevado a buen término la tarea de escapar a las tinieblas de la Edad Media sino el teatro ejemplar del Renacimiento? Por eso, el barroco fue releído en fines del siglo XIX como una degeneración del renacimiento, así como el decadentismo decimonono fue visto por las corrientes críticas progresistas del XX como una decadencia del romanticismo.

En el específico caso del análisis de Ángel Rama, que señala la diferencia entre los dos proyectos poéticos autonomistas, es decir, lo de Andrés Bello y lo de Darío, ocurre una tentativa de encontrar o de construir con la poesía de éste último un pasaje de la poesía ingenua del romanticismo para la poesía de orientaciones disidentes, más fuerte que el autonomismo oposicionista de Bello. Afirma, de esa manera, una virtud del decadentismo, allí no se puede tomar la poesía del modernismo como "el torpe renacimiento de la poesía europea", en contrario, señala que se trata de una poesía que tiene una destreza técnica incomparable. Sin embargo, con esta precisión técnica Rama no se priva de leerla también como fruto de "un extremismo peculiarmente hispanoamericano" (Rama, 1970:9). Este pensamiento de los extremos es tomado de modo muy productivo por Walter Benjamin en el libro sobre el barroco, cuando nos dice que los extremos más distantes y los aparentes excesos permiten la emergencia de la idea de un todo en el cual esté garantizado la coexistencia de los dichos opuestos. Lo toma también Georges Bataille como motivo de creación de lo posible-imposible; sin embargo, el pensamiento de lo extremo para el filosofo francés solamente se alcanza en la repetición, puesto que nunca hay seguridad de que se pueda aprehenderlo o no y, por eso, hay que repetir siempre. Para Ángel Rama este extremismo es lo que le daría a la poesía hispanoamericana su rasgo de originalidad en relación con la modernidad francesa, tomada como ejemplo de modernidad. Rama nos dice en Rubén Darío y el modernismo que:

Si en el modernismo aún se prolonga la imitación, el hecho de que el patrón oro de la poesía sea la originalidad y la búsqueda de la novedad, 
comienza a establecer una contención al proceso mimético. Pero aun en aquellos casos en que las similitudes son muy flagrantes entre los modelos franceses y las imitaciones hispanoamericanas, cabe reconocer que en estas últimas se registra un acento de autenticidad que faltaba en sus antepasados. (Rama, 1970:36)

En ese sentido se asoma la pregunta que construyó mi argumentación. ¿Qué significa tener "un acento de autenticidad"? ¿Con relación a qué somos auténticos? ¿Y por qué tenemos que pagar el precio de no ser latinoamericanos auténticos, autonómicos, progresistas, democráticos, cuando planteamos mimetizar?

Parto del punto de duda en que la lectura del libro El origen del drama barroco alemán me dejó. Si el drama barroco no es simplemente una copia mal hecha de la tragedia antigua, si los rasgos estilísticos no son suficientes para atribuirles a las obras su pendón autonómico, ¿en qué se constituiría la singularidad de una obra? Benjamin señala que los dramas barrocos se parecen a los dramas expresionistas contemporáneos suyos. Pero dice también que los dramas barrocos alemanes del siglo XVII son el otro extremo de la perfección y acabamiento de los dramas de Calderón de la Barca, justamente porque mimetizan mal el modelo renacentista, que era el griego. Y no era por eso que el drama barroco alemán no tenía qué decir a sus contemporáneos, incluso los contemporáneos suyos del fin del XIX y del XX. Benjamin anota una singularidad del barroco sobrevivido en el expresionismo de los inicios del siglo XX:

\begin{abstract}
El literato barroco se sentía permanentemente vinculado al ideal de un régimen absolutista como el que apoyaba la Iglesia de las dos confesiones. La actitud de sus actuales herederos es, si no revolucionaria y hostil al Estado, sí determinada por la ausencia de toda idea de Estado. Pero más allá de diversas analogías, no se debe olvidar una gran diferencia: en la Alemania del siglo XVII la literatura, por poca atención que le prestara la nación, contribuyó a su renacimiento de manera muy significativa. En cambio, los veinte años de letras alemanas a los que se ha hecho [aquí] referencia para explicar el renovado interés que muestran por la época, definen sin duda una decadencia, por inaugural y fructifera que sea. (Benjamin, 2006:256)
\end{abstract}

Es en ese sentido que me gustaría interrogar la supervivencia, o sea, sus modos y maneras, de las formas de la modernidad europea, incluso de la modernidad barroca de la Península lbérica del siglo XVII, en los modernistas hispanoamericanos Rubén Darío y Leopoldo Lugones, y en el brasileño Mário de 
Andrade, que no fue propiamente un modernista en el sentido de la historiografía literaria hispanoamericana, pero sacrificó su obra vanguardista, sacrificó la eternidad de su obra, en nombre de la producción de un pensamiento reflexivo sobre su país, es decir, transformó su obra en una obra de circunstancia, en una obra de ocasión, como las fueron las obras de los modernistas hispanoamericanos. ${ }^{1}$

\footnotetext{
${ }^{1}$ Le agradezco a Alberto Pucheu, con quien desarrollé un proyecto de trabajo sobre la poesía y el acontecimiento, el recuerdo de estas reflexiones de Mário de Andrade frente a la tarea de producir el acontecimiento de la poesía. En carta fechada el 10 de noviembre de 1924 a Carlos Drummond de Andrade, Mário de Andrade dice al amigo poeta que sacrifica la eternidad de su obra por el compromiso con la formulación de una teoría sobre la nacionalidad y sobre la nación brasileña.
}

(...) Nós temos que dar ao Brasil o que ele não tem e que por isso até agora não viveu, nós temos que dar uma alma ao Brasil e para isso todo sacrifício é grandioso, é sublime. E nos dá felicidade. Toda a minha obra é transitória e caduca, eu sei. E eu quero que ela seja transitória. Com a inteligência não pequena que Deus me deu e com os meus estudos, tenho a certeza de que eu poderia fazer uma obra mais ou menos duradoura. Mas que me importam a eternidade entre os homens da Terra e a celebridade? Mando-as à merda. Eu não amo o Brasil espiritualmente mais que a França ou a Cochinchina. Mas é no Brasil que me acontece vive e agora só no Brasil eu penso e por ele tudo sacrifiquei. A língua que escrevo, as ilusões que prezo, os modernismos que faço são pro Brasil. E isso nem sei se tem mérito porque me dá felicidade, que é a minha razão de ser da vida. Foi preciso coragem, confesso, porque as vaidades são muitas. Mas a gente tem a propriedade de substituir uma vaidade por outra. Foi o que fiz. A minha vaidade hoje é de ser transitório. Estraçalho a minha obra. Escrevo língua imbecil, penso ingênuo, só para chamar a atenção dos mais fortes do que eu pra este monstro mole e indeciso ainda que é o Brasil. Os gênios nacionais não são de geração espontânea. Eles nascem porque um amontoado de sacrifícios humanos anteriores Ihes preparou a altitude necessária de onde podem descortinar e revelar uma nação. Que me importa que a minha obra não fique? É uma vaidade idiota pensar em ficar, principalmente quando não se sente dentro do corpo aquela fatalidade inelutável que move a mão dos gênios. O importante não é ficar, é viver. Eu vivo. E vocês não vivem porque são uns despaisados e não têm a coragem suficiente pra serem vocês. É preciso que vocês se ajuntem a nós ou com este delírio religioso que é meu, do Osvaldo, de Tarsila ou com a clara serenidade e deliciosa flexibilidade do pessoal do Rio, Graça, Ronald. De qualquer jeito porque não se trata de formar escola com um mestrão na frente. Trata-se de ser. $E$ vocês por enquanto ainda não são. Responda, discuta, aceite ou não aceite, responda. Amigo eu serei sempre de qualquer forma. Não é a amizade e a admiração que diminuirão, é a qualidade delas. Amizade triste ou amizade alegre e do mesmo jeito a admiração. Desculpe essa longuíssima carta. Eu sofro de gigantismo epistolar. (...) (Andrade, 1987:23) 
En otra carta, fechada el 18 de febrero de 1925, Mário de Andrade reafirma que su arte está sacrificado por una utilidad que no es digna de las grandes obras de arte.

(...) Um dia, Drummond, quando eu tinha 20 anos mais ou menos eu comecei a ser artista. Lia versos e gostava. Depois comecei a escrevê-los e etc. Fiquei artista de verdade. Esse meu artistismo afinal deu num estouro de boiada: Paulicéia desvairada. Mas Paulicéia já não é inteiro arte. As "Enfibraturas do Ipiranga" não são arte. É polêmica e é teoria. Realmente continua o "Prefácio". Daí uma diferença essencial entre vocês, artistas legítimos, e eu que na realidade verdadeira não sou mais artista. Isto parece blague como outra qualquer mas não é. Continuo a embelezar minhas obras, torná-las agradáveis para interessar, atrair, convencer. Mas Ihes falta aquela qualidade artística primeira que uma infinidade de estetas e entre os últimos recentes Croce de maneira berrante estabeleceram: ausência de interesse prático, criação livre e pura do espírito. Minha arte, se assim você quiser, tem uma função prática, é originada, inspirada dum interesse vital e pra ele se dirige. Nisto sou tão primitivo como um homem das cavernas quaternárias. Só que além do interesse por assim dizer físico, interesse sexual, interesse de socialização, tenho ainda um interesse espiritual mais largo que o dele que só se dirigia aos deuses amedrontadores. Ainda é preciso distinguir entre primitivismo e primitivismo. Tem o que vem da precariedade técnica. Condenável. Tem o que vem da exata realização psíquica (Negros, Bizâncio, Puvis de Chavannes, Aleijadinho). Admirável e louvável. Tem o que vem da consciência duma época e das necessidades sociais, nacionais, humanas dessa época. É necessário. É intelectual, não abandona a crítica, a observação, a experiência e até a erudição. E só aparentemente se afasta delas. É o meu. É necessário. Minha arte aparente é antes de mais nada uma pregação. Em seguida é uma demonstração. Me seria certamente doloroso confessar isto se eu não fosse um homem que antes de mais nada vive e ama e se devotou inteiramente à vida e aos amores dele. E não o diria em público mas escolho a quem, e sei pra quem o digo. Minha vida é uma erupção de ardências de amor humano, eu só vivo pensando nas realizações desse amor. É natural pois que os motivos de inspiração nasçam do que toma todo o meu motivo de viver. Daí o lado intelectual, pregação, demonstração da minha pseudo-arte. Arte que se o for tem sempre um interesse prático imediato que nunca abandonou. Esta diferença essencial entre mim e vocês todos os demais modernistas do Brasil explica os sacrifícios de minha arte. Sacrifícios que o não são porque formam a realidade mais comovente, palpável e desejada por mim da minha vida. Eu não terei de pedir ao Pai que me afaste o cálix da boca porque me embebedo com ele deliciosamente. Aliás é repugnante esta comparação. Desculpe. (...) (Andrade, 1987:39-40)

Ángel Rama en Rubén Darío y el modernismo (7), señala esa fuerte y amplia diseminación de funciones de los escritores del primer modernismo, que vivían entre las funciones de educadores, moralistas, políticos y poetas. Y que eso los distinguiría de los escritores del segundo momento modernista que ya estarían más próximos a una especialización del arte de escribir:

A la independencia sustentada sobre la relativa novedad de una temática autóctona -"las gracias atractivas/de Natura inocente", como dice Bello antes de proceder a describir paisajes y contar hechos heroicos americanos-, opone la independencia más drástica que corresponde a una 
Para lo cual, me voy a detener en los fragmentos de tres piezas. Las elegí influenciada por la lectura de Walter Benjamin sobre el drama barroco, pero no podría dejar de darle el crédito a la investigación que Evandro de Sousa, cuyo trabajo sobre Mário de Andrade y el barroco brasileño dirijo, y a Raúl Antelo que en la comisión de evaluación del trabajo de Evandro de Sousa nos brindó a todos con muy valiosas sugestiones, especialmente ésta de confrontar las tres piezas: Pierrot y Colombina, la eterna aventura (1808), de Rubén Darío; El Pierrot negro (1909), de Leopoldo Lugones; y Café, obra inacabada de Mário de Andrade. Más que una homología entre las piezas intentaré mostrarles cómo superviven en un tiempo anacrónico los trazos de una cultura que se constituyó en el intervalo entre la decisión de ser arte y la circunstancia de mimetizar serlo, como lo que ocurre en la cultura barroca.

\section{Los gestos modernos latinoamericanos}

La pieza de Darío se propone ya en el título como una composición paralela al tiempo progresivo. La aventura de Pierrot y Colombina es eterna, pero, curiosamente, la publicó en un periódico y fue reunida después en un volumen dedicado precisamente a agrupar esos trabajos dispersos; aún así, esta eterna aventura es efímera como la página de un periódico. El Pierrot Negro de Lugones, escrito en 1909, por lo tanto, casi veinte años después de la de Darío, se incluye en su Lunario Sentimental. Es una pieza compuesta de cuatro cuadros y se asume como una pantomima; importante es señalar que ese tipo de pieza se caracteriza por la expresión gestual, lo que le da el carácter de drama, espectáculo teatral. No hay diálogos en el texto de Lugones, los cuadros son

reelaboración de la lengua poética, o sea, que traslada al lenguaje en función de poesía el afán autonómico, desdeñando su búsqueda en el campo temático en el cual muchas veces fue mero siervo de las modas que el Parnaso y el simbolismo impusieran a la poesía europea. Por esta oposición se comprende la distancia que hay entre la concepción del poeta civil de Bello, donde el artista cumple simultáneamente funciones de político, de ideólogo, de moralista y de educador, y la propia, más restricta y específica, de Darío. La tarea de éste se cumple en un campo estricto: la instauración de una poética. (Rama, 1970:7) 
cuadros, paisajes humanos compuestos de escenas, imágenes en las cuales lo humano se nos presenta como gesto. Mário de Andrade trabajó buena parte de su vida literaria en el proyecto de escribir Café. Lo que era antes un proyecto de una novela llena de psicología y vida intensa, como le cuenta Mário de Andrade a su amigo Manuel Bandeira en una carta fechada en julio de 1929, se transformó en 1942 en una pieza de teatro. ${ }^{2}$ La pieza Café lleva el subtítulo de "Tragedia Secular, el poema". Un poema trágico en el cual no hay personajes, por lo tanto no hay máscaras, maquillaje, y sin embargo hay drama: el de los empleados del puerto exportador de las riquezas del país, explotados al máximo por los dueños del capital agravada por la crisis de 1929 que aceleraba el proceso de decadencia de un sistema económico cuyo eje era la materia prima del grano de café. La pieza de Mário de Andrade se compone en cuadros en los cuales asoman hombres hambrientos tanto por alimento como por justicia; en otras palabras, se configura un paisaje violento, bárbaro y salvaje, propuesto y materializado también en una forma salvaje, si pensamos en los casos ejemplares de esa salvajería como lo son el drama trágico barroco o la ópera moderna. No sólo es interesante observar cómo la forma del poema y de la ópera se atraviesan sino cómo se conforman en la anteposición de una en la otra. Así que es también interesante pensar cómo la forma de la tragedia se atraviesa en la forma de la ópera. Está el coro, que lejos de funcionar como una mediación que todo lo sabe entre el público y la escena, usa su propia voz para ser la voz del espectador al cual se dirige: el pueblo. Los solistas, cuando los hay, articulan un lenguaje colectivo que se condice respecto de los gritos y berros del coro, del pueblo. En ese sentido, los solistas y el coro se constituyen en casi personajes tipos.

En las dos piezas anteriormente referidas Pierrot y Colombina, la aventura eterna, de Darío; y Pierrot Negro, de Lugones, hay igualmente personajes tipos

\footnotetext{
${ }^{2}$ En la carta, Mário de Andrade compara dos proyectos de trabajo suyos que estaban destinados a ser obras de arte, por lo tanto, más de lo que él pensaba que fueron:

E iniciei e gosto muito dum romance Café que terá oitocentas páginas (meio de contar o tamanhão do livro) cheias de psicologias e intensa vida. Mas sinto que é superior às minhas forças e tenho mais ou menos a conviç̧ão de que vou ratar, da mesma forma com que ratei Macunaíma -a obraprima que não ficou obra-prima. Mas não é por isso que vou parar o livro não. (Andrade, 2000:427)
} 
que enuncian un lenguaje colectivo y, para decirlo con más adecuación a la lectura que quiero producir, enuncian un lenguaje impersonal. La figura de Pierrot es una supervivencia de la figura del personaje Pedrolino de la "Commedia dell'arte". Sabemos que la "Commedia dell'arte" es el género de la comedia italiana de improviso, que apareció en Italia en el siglo XVI y se extiende hasta el siglo XVIII. El rasgo del espectáculo de la "Commedia dell'arte" que a mi lectura más interesa es que los actores seguían un esquema orientador de las acciones en el palco, pero también se ponían a merced de las circunstancias para emprender sus improvisaciones. Eso le daba al espectáculo un carácter colectivo. El habla de los personajes era substituido por los gestos ya memorizados en base a situaciones también ya interiorizadas tanto por el público como por los promotores del espectáculo. Los personajes tipos de la "commedia dell'arte" incluyen además del Pedrolino, Colombina, Polichinela y Arlequín. El más popular de ellos es Arlequín, el malandrín o "malandro", el que era capaz de producir situaciones inusitadas y por eso cómicas. No se puede olvidar que Mário de Andrade en el libro de poemas Paulicéia Desvairada, publicado en 1921, y una de las obras que funcionaron como manifiesto de la vanguardia brasileña en 1922; la figura del Arlequín es la que marca la relación del poema con la modernidad. ¿Y en qué se constituye esa relación?

La profesora Telê Ancona Lopez, una de las investigadoras de la Universidad de São Paulo, y dedicada a los estudios de la obra de Mário de Andrade, acerca la figura del Arlequín en este libro a lo que ella entiende como un vanguardismo adecuado "a las características sociales y culturales propias a ese país, Brasil, entendiendo al arte como expresión de la particularidad, determinada y concreta en el mundo". El vanguardismo arlequinesco de Paulicéia Desvairada para la estudiosa en cuestión es auténticamente moderno porque en los poemas ya asoma una reflexión crítica sobre la modernidad, reflexión crítica marcada por una expresividad idiosincrásica. No es para despreciar aquí la lectura que le hace el crítico brasileño Antonio Candido a la novela romántica Memórias de um sargento de milícias, de Manuel Antonio de Almeida, novela publicada en cuadernos del periódico Correio Mercantil do Rio de Janeiro entre 1852 y 1853, y que el crítico elige como la primera novela auténticamente nacional, brasileña, a la vez que el personaje principal de esa novela satírica deja de figurar con los 
rasgos de la tradición ibérica del héroe pícaro para presentarse como el primer "malandro" brasileño. Este ensayo de Antonio Candido, intitulado "A dialética da malandragem" (1968), juntamente con otros dos estudios suyos, promueve una discusión con el crítico y poeta brasileño Haroldo de Campos, en el que éste último señala el rechazo de la figura del pícaro por parte de la crítica nacionalista e identitaria de aquél. La figura del pícaro para Haroldo de Campos acercaba la tradición barroca a la modernidad en América Latina. Lo que Haroldo de Campos proponía era que la supervivencia de esas formas barrocas, y que eran renacentistas también, constituirían una historia de las formas, utilizando un término de Walter Benjamin, extraído del texto "La tarea del traductor"; formas allí entendidas no como estructuras sino como formas de la naturaleza, que él retoma a su vez de Goethe, en sus estudios de naturalista amador, que resultaron en libros como La metamorfosis de las plantas y La teoría de los colores. De ahí que, para Haroldo de Campos, la figura del pícaro, tanto en sus versiones arlequinescas y pierrotescas necesita de un tratamiento histórico, pero es una historia de las formas lo que se reivindica. Lo que molesta a Haroldo de Campos es que la crítica que busca encontrar un modelo ejemplar para la obra latinoamericana moderna -lo mismo pasa con las tentativas de calificar y clasificar las obras en la posmodernidad-, al ejecutar el juicio que se funda sobre los pilares de la "bio-grafía" de la nación establece en el mismo acto un lugar inferior en la tradición para lo que es premoderno, o lo que es anacrónico, sin tampoco pensarlos como problemas complejos que son.

Giorgio Agamben, en su estudio sobre el arte en la cultura italiana, y que nos sirve para ratificar este análisis de la poesía dramática en la modernidad latinoamericana, señala que la comedia no se distingue de la tragedia sino por los personajes. Dice que el Arlequín no es un personaje en el sentido que Hamlet o Edipo lo son; tomando como principio que las máscaras no son sujetos, pero gestos, y residuos de un sujeto tornado tipo, dividido entre el yo y el otro que lo constituye, Agamben nos propone que ocurre en la comedia una destrucción de la identidad tanto del personaje como del actor. Es la relación entre el texto y su ejecución, entre la potencia y el acto que aparece en la máscara pensada como mezcla indiferenciada de la potencia y del acto. Interesante aquí para este análisis de las formas del drama en la modernidad latinoamericana, es que lo que ocurre 
en la escena no es una actualización de las formas o figuras de la historia de esas formas, sino es que la liberación de su potencia venidera. Con eso, el gesto, la máscara, se torna un fragmento de vida sustraído del contexto de una biografía individual; es decir, como lo dice Agamben, se transforma en un fragmento de arte sustraído del contexto de la neutralidad estética, se torna pura praxis. ${ }^{3}$

Si Antonio Candido reconoce en el héroe de la novela romántica Memórias de um sargento de milícias, el primer "malandro" de la literatura brasileña, o sea, el primer personaje de una literatura nacional, es porque encarna en su biografía todas las peculiaridades de la vida social. No olvidemos que Agamben también nos dice que los gestos a los que se reducen los personajes biográficos lejos de ser moneda de cambio y de uso, permiten que se precipiten en la escena los "cristales de esta sustancia social común". Tenemos en los análisis de Ángel Rama sobre Rubén Darío y sobre el modernismo, al igual que el del crítico brasileño Antonio Candido, una búsqueda de rasgos en las obras que les permiten construir un discurso nacional acerca de aquello que es, en verdad, un "cristal de esta sustancia social común". Por eso, es más cómodo aproximar a los héroes de la modernidad latinoamericana a los héroes, que también son tipificados, de las obras de Molière e Maviraux; sus Pierrots y sus Arlequines ya pasaron por la ilustración francesa, por lo tanto, son menos salvajes, menos bárbaros, menos "tipos", que los pícaros ibéricos y los reyes alemanes del drama alemán. Los héroes tipificados de la comedia francesa pasaron por un proceso de "melancolización” y subjetivización. Entretanto, y desde otra perspectiva, el poeta decadente francés Jules Laforgue mezcló la figura de Pierrot a la del poeta moderno. La figura de Pierrot de Complaites de Lord Pierrot de Laforgue, presenta a un "dandy" filosofante con un corazón casto y dulce, "chaste et doux". Sabemos desde Baudelaire que los "dandis" son figuras, son gestos sin biografía, puesto que los convoca a todos a una obediencia ciega, a las reglas de la nueva secta: el dandismo. Pero no es a este Pierrot que tanto las lecturas de Candido como las de Rama se conectan.

\footnotetext{
${ }^{3}$ Giorgio Agamben, en "Glosas marginales a los Comentarios de la sociedad de lo espectáculo de Guy Debord", texto de presentación de la traducción italiana de Comentarios sobre la sociedad del espectáculo, disponible en revista Multitudes:

http://multitudes.samizdat.net/Gloses-marginales-aux Commentaires?var recherche=agamben).
} 
Es aquí donde a mí me gustaría concentrarme para terminar este trabajo; con algo más vasto que la condición de mi investigación en este momento. El proceso de modernización en América Latina para los dos críticos latinoamericanos obedece a los reclamos capitalistas del liberalismo europeo. Sin embargo, tanto Antonio Candido como Ángel Rama, intentaron en sus trabajos rever sus tesis cuando depararon el problema de las supervivencias de las formas culturales y literarias precapitalistas en la literatura. Candido lo retoma al afirmar en el ensayo "Dialetica da malandragem", que en la novela "Memórias de um sargento de milícias" la literatura brasileña gana su primer "malandro"; lo que lo distinguía de las formas de la picardía europea por su carácter eminentemente local, y por lo tanto, insertado en la modernidad nacional y latinoamericana. Rama a su vez, en Las máscaras democráticas del modernismo, retoma su análisis del modernismo, aunque bajo la perspectiva de la "ciudad letrada". Con la intención de repensar las afirmaciones de que el modernismo latinoamericano sufría de una "inadecuación" frente a la modernidad europea, con su "parcial actitud servil imitativa", y que la poesía moderna latinoamericana debía al modernismo su "nutrición" puesto que "estableció las bases de una creación autónoma y vigente" (Rama, 1970:125), en el capítulo dedicado a pensar el arte de la democratización, reafirma en su análisis la búsqueda de una literatura nacional moderna y occidental. La poesía modernista para Rama no pasa de una construcción poética de la nacionalidad, y esta es su novedad en relación con los análisis historicistas, por eso dice que el simbolismo "no rompe el proceso renovador que venía desde los setenta, ni se opone a él, sino que le suma" (Rama, 1985:66). Con eso no está lejos de afirmar que la palabra "modernismo significa actualización" (69). En el capítulo siguiente, Rama se dedica a analizar la función de lo que él llama de "guardarropía histórica de la sociedad burguesa", eligiendo la categoría de la máscara para leer el proceso de democratización de la sociedad moderna latinoamericana y europea como ideológica. La guardarropía es vista como signo del "eclectismo" "exótico" y "abigarrado", y las máscaras son el signo del "deseo", que es erótico por excelencia, en su "faz de apetito de goce y de apetito de poder" (87).

Giorgio Agamben, conforme señalado ya en este texto, destaca que el lugar de la máscara es entre el texto y su ejecución y es en él que se mezclan la 
potencia y el acto, de ahí que la máscara no puede ser vista sino como liberación de una potencia ulterior, y no como una actualización de la potencia. El filósofo italiano Mario Perniola en su estudio sobre el arte italiano y contemporáneo afirma que una filosofía del presente y de la presencia debe estar en el polo opuesto del pensamiento negativo y de las distintas formas que ha asumido el pensamiento de la crisis. Para el autor del libro Enigmas la filosofía del presente realmente eficaz...

\begin{abstract}
...no lamenta la ausencia de nada, no está de luto por la pérdida de algún valor o ideal, ni de alguna identidad positiva. En primer lugar, porque los valores y los ideales son desde siempre por definición demasiado irreales y abstractos; en segundo lugar porque ésta [la filosofía del presente] se apropia, asume dentro de sí todo lo que de positivo el pasado transmite. Contrariamente a la imagen de un mundo vacío, de una kénosis, que caracterizaría la sociedad actual, mi búsqueda está animada por la imagen de un mundo lleno, de un pléroma, en el que todo está a disposición. La noción de simulacro no debe ser entendida como sinónimo de mentira o engaño -según una perspectiva metafísica que opone lo verdadero a lo falso y por eso condena cualquier duplicado- sino justo al contrario como garantía de la dignidad de la copia, de su derecho a durar: la importancia de la noción de simulacro está justamente en el hecho de que ésta acentúa y subraya la presencia física del pasado en el presente. (Perniola, 2006:56)
\end{abstract}

Así que en el análisis de la literatura latinoamericana los valores de una identidad auténtica y nacional no pueden pasar de un intento ingenuo frente a la complejidad de lo real. Ser copia o no, ser simulacro de modernidad o no, estar en dirección hacia un valor idealizado como es el valor de la autenticidad de una producción nacional y moderna, realmente sólo importa si no comprendemos el mundo como signo del eclectismo, del exotismo, que "mascararían el deseo erótico por el goce y el poder". Importa pensar cómo ese imaginario nos produce a todos. Y esta es la pregunta -"está por estudiarse el efecto que en el imaginario latinoamericano produjo la modernización" (Rama, 1985:101)- que el propio Rama se hace en Las máscaras democráticas del modernismo. Pero él no consigue responderla, quizás por las condiciones que rodean la edición del libro, que no estaba terminado y fue publicado después de su muerte por sus alumnos y discípulos.

En su ponencia presentada en 2003 en la reunión de la Latin American Studies Association, "Rama y la modernidad secuestrada", Raúl Antelo destaca 
que "Ángel Rama, gracias a su programa cultural de inclusión progresiva, toma distancia de la economía generalizada, el mimetismo y lo Real, es decir, del ideal de felicidad" (Antelo, 2003). En otro ensayo el crítico retoma esta cuestión, y siempre con la lectura que desarrolla, con esa mirada por la apertura del mundo, en pos de producir una crítica viva y, sobre todo, en conexión con la vida, pregunta:

¿La América Latina unificada bajo la divisa de lo moderno, es similis, aunque siempre secundaria, de Europa o simultánea de su matriz? El análisis de Agamben superpone, problemáticamente, dos líneas de trabajo aparentemente enfrentadas en esos diagnósticos de los años '70: la de la simultas, que atraviesa el pensamiento de Rodriguez Monegal, José Luis Martinez o Ángel Rama, y la de simulare, presente en las lecturas de Severo Sarduy o Haroldo de Campos. (Antelo, 2008:2)

Y con esto se asoma la pregunta con la que termino en clave de abertura este ensayo: ¿será que tendremos el coraje de pensar nuestra cultura sobre las bases del simulacro y de la simulación? En otras palabras, ¿tendremos la audacia de pensar nuestros documentos de cultura igualmente como documentos de barbarie? 


\section{Bibliografía}

Agamben, G. (1995): "Glosas marginales a los Comentarios de la sociedad del espectáculo de Guy Debord", texto de presentación de la traducción italiana de Comentari a la società dello spettacolo; SugarCo, Carnago. Disponible en revista Multitudes (http://multitudes.samizdat.net/Gloses-marginalesauxCommentaires?var recherche=agamben).

Ancona Lopez, T. P. (1970): “Arlequim e Modernidade”, en Revista do Instituto de Estudos Brasileiros, № 21. USP, São Paulo, 88.

Andrade, M. (2000): Correspondência. Mário de Andrade y Manuel Bandeira. Organização, introdução e notas Marco Antonio de Moraes. Edusp/IEB, São Paulo.

(1987): A Lição do Amigo. Cartas de Mário de Andrade a Carlos Drummond de Andrade. Record, Rio de Janeiro.

Antelo, R.: "Rama y la modernidad secuestrada", en http://www.beatrizviterbo.com.ar.

(2008): "Una crítica acéfala para la modernidad latinoamericana", en Revista Iberoamericana, año VIII, N³3. Madrid/Hamburgo.

Candido, A. (1998): "Dialética da malandragem", en O discurso e a cidade. Livraria Duas Cidades, São Paulo.

(1987): “A literatura de dois gumes”, en A educação pela noite. Ática, São Paulo. (1975): A formação da literatura brasileira. Itatiaia, Rio de Janeiro.

Bataille, G. (2004): "La voluntad de lo imposible", en La felicidad, el erotismo y la literatura. Ensayos 1944-1961. Adriana Hidalgo, Buenos Aires. (Traducción, selección y prólogo de Silvio Mattoni).

Benjamin, W. (2006): "Origen del drama barroco alemán”, en Libro I, Obras. Abada, Madrid. (Traducción al español de Alfredo Muñoz).

(1967): "La tarea del traductor", en Ensayos Escogidos. Editorial Sur, Buenos Aires. (Traducción de Héctor Murena).

Goethe, J. W. (1997): A Metamorfose das plantas. Antroposófica, São Paulo. (Traducción al portugués de Friedhelm Simple).

Rama, Á. (1985): Las Máscaras democráticas del Modernismo. Fundación Ángel Rama, Montevideo. 
(1970): Rubén Darío y el Modernismo: circunstancias socio-económicas de un arte americano. Ediciones de la Universidad Central de Venezuela, Caracas.

Perinola, M. (2006): Enigmas. Egipcio, barroco y neo-barroco en la sociedad y el arte. Cendeac, Murcia. 